\title{
STUDIES OF THE PULMONARY CIRCULATION IN MAN AT REST. NORMAL VARIATIONS AND THE INTERRELATIONS BETWEEN \\ INCREASED PULMONARY BLOOD FLOW, ELEVATED PULMONARY ARTERIAL PRESSURE, AND HIGH PULMONARY “CAPILLARY" PRESSURES "
}

\author{
By L. DEXTER, J. W. DOW,2 F. W. HAYNES, J. L. WHITTENBERGER, B. G. FERRIS, \\ W. T. GOODALE, ${ }^{3}$ AND H. K. HELLEMS ${ }^{3}$ \\ (From the Medical Clinic, Peter Bent Brigham Hospital, the Department of Medicine, Harvard \\ Medical School, and the Department of Physiology, Harvard School of Public Health)
}

(Submitted for publication October 31, 1949; accepted, January 16, 1950)

While many studies have been carried out on the dynamics of the pulmonary circulation in experimental animals, few studies of this subject have been made in man until recently. With the advent of the cardiac catheter (1) it has become possible to make critical observations on the lesser circulation in health and disease.

The volume of blood flowing through the pulmonary artery per unit of time is dependent upon the pressure in the pulmonary artery, the resistance to blood flow offered by the pulmonary vasculature, and the ability of the left side of the heart to handle the volume of blood which it receives. In this paper, the resting values for pulmonary blood flow, pulmonary arterial pressure, pulmonary "capillary" pressure, the pulmonary artery-pulmonary "capillary" pressure gradient, and the pulmonary arteriolar resistance are presented. In addition, the interrelationships of these various components of the pulmonary circulation as affected by increased blood flow through the lung, by elevated pressures in the pulmonary artery, and by high pressures in the pulmonary capillaries have been analyzed.

\section{METHODS}

Patients were studied in a fasting state or else an hour or more following a light breakfast of black coffee, toast, and jam. Cardiac catheterization was carried out in the usual fashion. Pulmonary "capillary" pressure was measured as described elsewhere (2). The catheter was then withdrawn to the pulmonary artery in the region of the

\footnotetext{
1 This study was supported by a grant from the Life Insurance Medical Research Fund, and the National Heart Institute, U. S. Public Health Service.

2 This work was done during the tenure of a National Institutes of Health Postdoctorate Fellowship.

8 This work was done during the tenure of a Life Insurance Medical Research Fellowship.
}

bifurcation. A No. 21 needle connected with a saline drip was introduced into either the radial or brachial artery. When pulse and respiratory rates were stable, cardiac output was determined by the direct Fick principle. Expired air was collected for three minutes in a Douglas bag. The volume was measured in a Tissot spirometer. Oxygen and carbon dioxide concentrations were measured by the Haldane-Henderson method. In some experiments oxygen alone was measured by the Pauling oxygen analyzer. Midway during collection of the expired air, blood samples were withdrawn from the pulmonary and from the systemic arteries simultaneously and analyzed for oxygen content, capacity, and saturation by the method of Van Slyke and Neill (3) and the arteriovenous oxygen difference calculated. Pressures were recorded in the pulmonary artery and systemic artery simultaneously immediately after withdrawal of blood samples.

In patients investigated early in this study, pulmonary blood flow was calculated from data obtained as follows (4) : oxygen consumption was determined by the Benedict-Roth method before cardiac catheterization; mixed venous blood was subsequently obtained from the pulmonary artery through the catheter; and a sample of brachial or femoral arterial blood was taken after the catheter had been withdrawn from the body. Cardiac outputs calculated in this way may be recognized in the tables by absence of data in the column for oxygen consumption by expired air. As regards the accuracy of this method of determining cardiac output, little error was introduced in the arterial sampling, since none of the patients with mitral stenosis and cardiac failure had arterial oxygen unsaturation. Since in congenital heart disease with shunts there is gross error in the calculation of blood flow (4), any refinement of technique by simultaneous sampling would still leave a considerable error of uncorrectable magnitude and direction. The main error, therefore, consists in the accuracy of the oxygen consumption. In 55 cases in our laboratory, the average basal oxygen consumption with the BenedictRoth machine was $210 \mathrm{cc}$. per min. and by expired air at the time of cardiac catheterization $228 \mathrm{cc}$. per min. with a standard error of \pm 7.4 . Although blood flow calculated in this way is not so accurate for analytical purposes as when all measurements are obtained simul- 
taneously, the error of calculation does not alter in any way the conclusions drawn in this paper.

Pressures were recorded with Hamilton manometers (5) or in the latter part of the series with electromanometers 4 (6) recording on a multichannel, direct writing oscillograph. A saline manometer was used for checking mean pressures but not for analytical purposes. Mean pressures were obtained by planimetric integration of the pressure tracings, using the Hamilton manometer, and by electrical integration of the oscillograph tracings which in our hands by actual comparison was more accurate than mechanical planimetry. The pressure gradient between pulmonary artery and pulmonary "capillaries" was obtained by subtraction. The zero point for all pressures was $10 \mathrm{~cm}$. anterior to the back with the patient recumbent.

Pulmonary arteriolar resistance was calculated as follows :

$\mathrm{R}=\frac{\mathrm{PA}_{\mathrm{m}}-\text { " } P \mathrm{C}_{\mathrm{m}} \text { " }}{Q / \mathrm{t}} \times 1332$ expressed in dynes seconds $\mathrm{cm} .^{-s}$ where $\mathbf{P A}_{m}=$ mean pressure in the pulmonary artery, " $\mathrm{PC}_{\mathrm{m}}$ " = mean pressure in the pulmonary "capillaries," $Q / t=$ cardiac output in cc. per second, and 1332 the conversion factor from $\mathrm{mm}$. $\mathrm{Hg}$ to dynes per $\mathrm{cm} .{ }^{2}$ The term "arteriolar" resistance is used in the physiological sense, since there are no vessels in the lung having the anatomical characteristics of systemic arterioles. In his book, Miller (7) avoids the word. In the physiological sense, however, it is used to designate small vessels between the large arteries into which the catheter is wedged and the true pulmonary capillaries.

Work of the heart consists of work against pressure and work done in accelerating the blood (kinetic work)

(8). The latter cannot be readily computed in man, al-

4 Sanborn Company. though Prec and his associates (9) have recently attempted to do so. Work against pressure is equal to the product of stroke or cardiac output and mean systolic ejection pressure. The measurement of the latter is inaccurate by present methods of recording ventricular pressures through a catheter, because of the debatable fidelity of the ventricular pressure curves due to artefacts produced by the catheter. For similar reasons, Riley and his colleagues (10) used the product of the mean pressure in the pulmonary artery and the cardiac output as a measure of work of the right ventricle. The authors were fully aware that this represented peripheral work rather than work of the heart and quoted Remington and Hamilton (8) as showing that values so obtained were some 10 per cent to 40 per cent lower than the true value for ventricular work against pressure. We have calculated the pulmonary peripheral work as an approximation of the work of the right ventricle against pressure in the same way, with the realization that the work of the ventricle is actually greater than these figures show. The calculation is as follows (11): Work of the right ventricle against pressure (actually pulmonary peripheral work) $=$ $\frac{(\mathrm{CI} \times 1.055)\left(\mathrm{PA}_{\mathrm{m}} \times 13.6\right)}{1000}$ kilogram meters per min. per square meter body surface, where $\mathrm{CI}=$ cardiac index in liters per min. per square meter body surface, $1.055=$ specific gravity of blood, $\mathbf{P A}_{\mathbf{m}}=$ mean pressure in the pulmonary artery in $\mathrm{mm}$. $\mathrm{Hg}$, and $13.6=$ specific gravity of mercury.

\section{A. NORMAL VARIATIONS}

Eight patients were considered to have normal cardiovascular-pulmonary systems by history, physical examination, fluoroscopy of the heart and lungs, and electrocardiogram. Four were con-

TABLE I

Pulmonary pressures, flows, and arteriolar resistances in normal patients at rest

\begin{tabular}{|c|c|c|c|c|c|c|c|c|c|c|c|c|c|c|c|}
\hline \multirow[b]{2}{*}{ そั } & \multirow{2}{*}{ 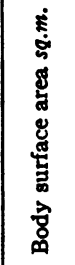 } & \multirow{2}{*}{ 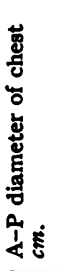 } & \multicolumn{3}{|c|}{$\begin{array}{l}\text { Pulmonary artery } \\
\text { pressure } \\
\text { mm. Hg }\end{array}$} & \multirow{2}{*}{ 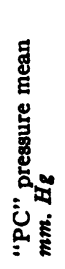 } & \multirow{2}{*}{ 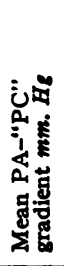 } & \multirow{2}{*}{ 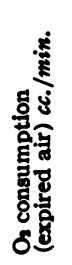 } & \multirow[b]{2}{*}{ 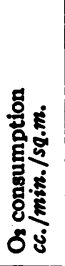 } & \multirow{2}{*}{ 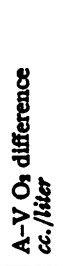 } & \multirow{2}{*}{ 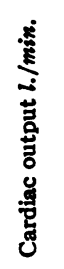 } & \multirow[b]{2}{*}{ 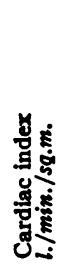 } & \multirow{2}{*}{ 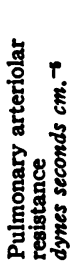 } & \multirow{2}{*}{ 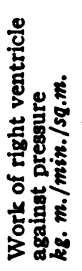 } & \multirow[b]{2}{*}{ Diagnosis } \\
\hline & & & 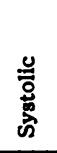 & 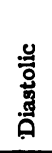 & స్ & & & & & & & & & & \\
\hline $\begin{array}{l}\text { A. F. } \\
\text { E. F. } \\
\text { M. } \mathbf{M} .\end{array}$ & $\begin{array}{l}1.98 \\
1.73 \\
1.48\end{array}$ & $\begin{array}{l}19 \\
20 \\
15\end{array}$ & $\begin{array}{l}25 \\
26 \\
24\end{array}$ & $\begin{array}{l}12 \\
10 \\
10\end{array}$ & $\begin{array}{l}15 \\
15 \\
17\end{array}$ & $\begin{array}{r}8 \\
7 \\
12\end{array}$ & $\begin{array}{l}7 \\
8 \\
5\end{array}$ & $\begin{array}{l}316 \\
247 \\
236\end{array}$ & $\begin{array}{l}160 \\
143 \\
160\end{array}$ & $\begin{array}{l}32 \\
33 \\
36\end{array}$ & $\begin{array}{l}9.9 \\
7.5 \\
6.6\end{array}$ & $\begin{array}{l}5.0 \\
4.3 \\
4.5\end{array}$ & $\begin{array}{l}56 \\
85 \\
61\end{array}$ & $\begin{array}{l}1.08 \\
0.93 \\
1.10\end{array}$ & $\begin{array}{l}\text { Normal } \\
\text { Primary syphilis, treated } \\
\text { Congenital syphilis, }\end{array}$ \\
\hline $\begin{array}{l}\text { W. P. } \\
\text { U. M. } \\
\text { D. W. W. } \\
\text { L. F. } \\
\text { H. H. }\end{array}$ & $\begin{array}{l}1.65 \\
1.62 \\
1.77 \\
1.96 \\
1.87\end{array}$ & $\begin{array}{l}19 \\
18 \\
15 \\
20 \\
18\end{array}$ & $\begin{array}{l}22 \\
23 \\
19 \\
25 \\
19\end{array}$ & $\begin{array}{r}6 \\
6 \\
11 \\
8 \\
7\end{array}$ & $\begin{array}{l}14 \\
13 \\
15 \\
16 \\
13\end{array}$ & $\begin{array}{r}9 \\
9 \\
6 \\
11 \\
7\end{array}$ & $\begin{array}{l}5 \\
4 \\
9 \\
5 \\
6\end{array}$ & $\begin{array}{l}228 \\
214 \\
298 \\
252 \\
235\end{array}$ & $\begin{array}{l}138 \\
132 \\
168 \\
128 \\
127\end{array}$ & $\begin{array}{l}35 \\
31 \\
36 \\
47 \\
30\end{array}$ & $\begin{array}{l}6.5 \\
6.8 \\
8.3 \\
5.4 \\
7.8\end{array}$ & $\begin{array}{l}3.9 \\
4.2 \\
4.7 \\
2.8 \\
4.2\end{array}$ & $\begin{array}{l}62 \\
47 \\
87 \\
74 \\
62\end{array}$ & $\begin{array}{l}0.79 \\
0.78 \\
1.01 \\
0.64 \\
0.78\end{array}$ & $\begin{array}{l}\text { Primary syphilis, treated } \\
\text { Primary syphilis, treated } \\
\text { Normal } \\
\text { Normal } \\
\text { Normal }\end{array}$ \\
\hline \multicolumn{3}{|c|}{ Average } & 23 & 9 & 15 & 9 & 6 & 253 & 145 & 35 & 7.4 & 4.2 & 67 & 0.89 & \\
\hline
\end{tabular}

$\mathrm{PA}=$ Pulmonary artery mean pressure.

"PC" = Pulmonary "capillary" mean pressure. 
sidered to be normal in all respects. Three had primary syphilis and one congenital syphilis; all had been under treatment with penicillin for at least 48 hours before these studies were undertaken.

The data in Table I indicate that in this group of normal patients the pulmonary artery systolic pressure varied between 19 and 26 with an average of $23 \mathrm{~mm}$. $\mathrm{Hg}$, the diastolic between 6 and 12 with an average of $9 \mathrm{~mm}$. $\mathrm{Hg}$, and the mean between 13 and 17 with an average of $15 \mathrm{~mm}$. $\mathrm{Hg}$. The pulmonary "capillary" mean pressure ranged from 6 to 12 with an average of $9 \mathrm{~mm}$. $\mathrm{Hg}$, which is in agreement with values previously reported (2). The gradient of pressure between pulmonary artery and pulmonary "capillaries" averaged $6 \mathrm{~mm}$. Hg with a range of 4 to 9 . The arteriolar resistance varied between 47 and 87 dynes seconds $\mathrm{cm} .^{-5}$ with an average of 67.

In these patients, oxygen consumption varied between 127 and 168 cc. per min. per sq.m. with an average of 145 , the arteriovenous oxygen difference varied from 30 to 47 and averaged $35 \mathrm{cc}$. per liter, and cardiac index ranged between 2.8 and 5.0, the mean being 4.2. Work of the right ventricle against pressure, as calculated, varied between 0.64 and $1.10 \mathrm{~kg} . \mathrm{m}$. per min. per sq.m. body surface, the average being 0.89 .

\section{Comment}

Others $(10,12)$ have shown that pulmonary artery mean pressures are normally within the range reported here, being only about 15 per cent of the magnitude of the pressure in the systemic circuit.

The pulmonary "capillary" pressure in this group of patients averaged $9 \mathrm{~mm}$. $\mathrm{Hg}$. The zero point for the recording of all pressures was taken $10 \mathrm{~cm}$. anterior to the back with the patient recumbent (13). It is to be emphasized that this was an arbitrary zero point used in relation to what was assumed to be the position of the right auricle. For the determination of the effective hydrostatic pressure of blood in the capillaries, the intrathoracic pressure would have to be measured and the exact position of the tip of the catheter would have to be used as the point of zero reference. Bearing these features in mind, it is apparent that the true capillary pressure in the lung was much lower than the value of $25 \mathrm{~mm}$. $\mathrm{Hg}$ that exists in the peripheral capillaries, at least of the skin (14), and that the alveolar spaces are, from the point of view of hydrodynamic-osmotic relationships, well protected against the development of pulmonary edema.

The pulmonary "capillary" pressure approximated the diastolic pressure in the pulmonary artery and the averages for the eight patients were identical. In four of the eight cases, the pulmonary "capillary" mean pressure as measured was as much as $3 \mathrm{~mm}$. $\mathrm{Hg}$ higher than the diastolic pressure in the pulmonary artery. Since, however, the pulmonary "capillary" pressure was expressed as a mean pressure, it cannot be stated from these figures that the diastolic pressure in the pulmonary artery was at any instant lower than the corresponding "capillary" pressure.

The gradient of mean pressures between pulmonary artery and pulmonary "capillaries" was low, averaging $6 \mathrm{~mm}$. $\mathrm{Hg}$, as compared with the systemic circuit where it is normally about 10 times higher. With a blood flow equal to that in the systemic circulation, it follows that the arteriolar resistance to blood flow in the lungs is small. As seen in Table I, pulmonary arteriolar resistance averaged 67 dynes seconds $\mathrm{cm}^{-5}$ (15).

In several recent publications $(10,16,17)$ pulmonary vascular resistance has been calculated assuming an arbitrary figure for pressure in the left atrium. In our experience, such an assumption is occasionally subject to considerable error. Hickam $(18,19)$, however, measured pulmonary venous pressure in four patients with atrial septal defect and was able to calculate accurately the pulmonary arteriolar resistance.

Cournand and his associates (20) have reported that under standard basal conditions in 13 normal subjects, oxygen consumption was $138 \pm 14$ cc. per min. per sq.m., the arteriovenous oxygen difference was $45 \pm 7 \mathrm{cc}$. per liter, and the cardiac index was $3.12 \pm 0.40$ liters per min. per sq.m. In the patients reported here, the averages were as follows : oxygen consumption $145 \mathrm{cc}$. per min. per sq.m., arteriovenous oxygen difference $35 \mathrm{cc}$. per liter, and cardiac index 4.2 liters per min. per sq.m. This elevation of cardiac output and narrowing of the arteriovenous oxygen difference is a characteristic finding in patients who are somewhat anxious and not relaxed (21). Like values have been found by others $(12,22)$ when similarly 
complicated procedures have been carried out, using the cardiac catheter. Other studies were carried out in the majority of these patients, particularly subsequent periods of exercise which will be reported in another communication. We believe that values for pressures, gradients, and arteriolar resistance would be little altered from those reported here by the observance of a strictly basal state because little, if any, measurable change in these values appears until the minute oxygen consumption per square meter of body surface becomes more than double the figures reported here $(10,12,15)$.

The work of the right heart against pressure, or more properly the pulmonary peripheral work, averaged $0.89 \mathrm{~kg}$. m. per min. per sq.m. body surface ( 8 joules per min. per sq.m. body surface). Riley and his colleagues (10) observed an average value of 5 joules per min. per sq.m. in three normal patients at rest. From their data, it is apparent that their patients were in a more nearly basal state than those reported here. This obviously accounts for the somewhat higher values in our patients.

\section{B. EFFECTS OF INCREASED PULMONARY BLOOD FLOW}

Seven patients with atrial septal defect and two with patent ductus arteriosus were studied. In each, pulmonary blood flow was higher than nor- mal and in each the diagnosis was confirmed by cardiac catheterization (23). Pulmonary blood flow was calculated in the usual manner, assuming a pulmonary venous oxygen saturation of 98 per cent. The purpose was to observe the effect of increased flows upon the pulmonary artery pressure and the pressure gradient across the lung. Patients with increased pulmonary arteriolar resistances or elevated pulmonary "capillary" pressures were excluded because both of these factors are associated with abnormal elevations of pressure in the pulmonary artery.

Space does not suffice to present the oxygen content of blood samples obtained from the pulmonary artery and right heart chambers in these individuals. These will be reported in detail in another communication. In all cases, however, samples of blood were withdrawn from the right or left branch of the pulmonary artery within 4 or $5 \mathrm{~cm}$. of its bifurcation; in six cases a duplicate sample was withdrawn from the main stem of the pulmonary artery and in the remaining three from the outflow tract of the right ventricle. In all instances values for oxygen content were in close agreement. The error involved in calculating blood flows by the direct Fick principle in individuals with narrow arteriovenous oxygen differences as in Cases 8 and 9 of Table II has previously been discussed (4).

TABLE II

Pulmonary pressures, flows, and arteriolar resistances in resting patients with left-to-right shunts

\begin{tabular}{|c|c|c|c|c|c|c|c|c|c|c|c|c|c|}
\hline \multirow[b]{2}{*}{ 莺 } & \multirow{2}{*}{ 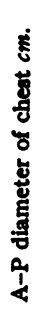 } & \multicolumn{3}{|c|}{$\begin{array}{l}\text { Pulmonary artery pressures } \\
\mathbf{m m} . \mathrm{Hg}_{\boldsymbol{g}}\end{array}$} & \multirow{2}{*}{ 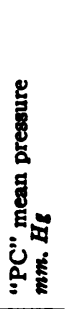 } & \multirow{2}{*}{ 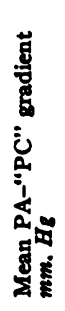 } & \multicolumn{2}{|c|}{$\begin{array}{l}\text { Oxygen } \\
\text { consumption } \\
c c . / m i n .\end{array}$} & \multirow{2}{*}{ 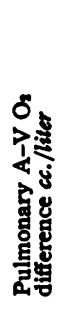 } & \multirow{2}{*}{ 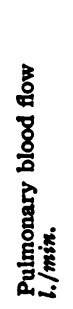 } & \multirow{2}{*}{ 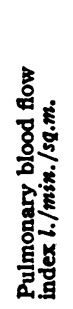 } & \multirow{2}{*}{ 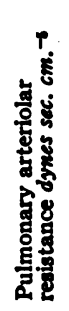 } & \multirow[b]{2}{*}{ 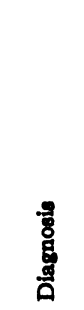 } \\
\hline & & 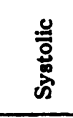 & $\begin{array}{l}0 \\
\stackrel{0}{\circ} \\
\text { 总 } \\
\end{array}$ & శ్ & & & $\frac{\overrightarrow{6}}{\not{g}}$ & 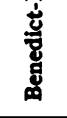 & & & & & \\
\hline $\begin{array}{l}\text { M. C. } \\
\text { R. S. } \\
\text { V. C. } \\
\text { B. K. } \\
\text { J. V. } \\
\text { S. L. } \\
\text { S. Y. } \\
\text { S. W. } \\
\text { F. M. }\end{array}$ & $\begin{array}{l}15 \\
17 \\
20 \\
16 \\
21 \\
14 \\
18 \\
-\end{array}$ & $\begin{array}{l}23 \\
27 \\
24 \\
25 \\
30 \\
32 \\
40 \\
41 \\
45\end{array}$ & $\begin{array}{r}10 \\
8 \\
13 \\
11 \\
15 \\
12 \\
20 \\
21 \\
23\end{array}$ & $\begin{array}{l}19 \\
12 \\
17 \\
18 \\
20 \\
24 \\
23 \\
30 \\
37\end{array}$ & $\begin{array}{r}14 \\
4 \\
9 \\
8 \\
10 \\
12 \\
5 \\
10 \\
14\end{array}$ & $\begin{array}{r}5 \\
8 \\
8 \\
10 \\
10 \\
12 \\
18 \\
20 \\
23\end{array}$ & $\begin{array}{l}185 \\
\overline{-} \\
177 \\
276 \\
222 \\
\overline{-} \\
227\end{array}$ & $\begin{array}{l}120 \\
197 \\
198 \\
143 \\
270 \\
204 \\
165 \\
183 \\
183\end{array}$ & $\begin{array}{r}17 \\
18 \\
18 \\
15 \\
8 \\
15 \\
13 \\
6 \\
8\end{array}$ & $\begin{array}{l}10.9 \\
11.0 \\
11.0 \\
11.8 \\
34.5 \\
14.8 \\
12.7 \\
30.5 \\
27.0\end{array}$ & $\begin{array}{r}8.5 \\
7.3 \\
7.1 \\
8.6 \\
16.3 \\
9.5 \\
10.4 \\
19.3 \\
18.3\end{array}$ & $\begin{array}{r}37 \\
58 \\
58 \\
68 \\
23 \\
65 \\
113 \\
52 \\
68\end{array}$ & $\begin{array}{l}\text { PDA } \\
\text { ASD } \\
\text { ASD } \\
\text { ASD } \\
\text { ASD } \\
\text { ASD } \\
\text { ASD } \\
\text { ASD } \\
\text { PDA }\end{array}$ \\
\hline
\end{tabular}

$\mathrm{PA}=$ Pulmonary artery mean pressure.

"PC" = Pulmonary "capillary" mean pressure.

ASD $=$ Atrial septal defect.

PDA = Patent ductus arteriosus. 
Pertinent data are given in Table II and plotted become elevated, that in the pulmonary "capilin Figure 1. When pulmonary blood flows ex- laries" remained within normal limits, and the ceeded about 10 liters per min. per sq.m. body PA-"PC" pressure gradient became definitely surface, pressure in the pulmonary artery began to wider. Since patients with an elevated pulmonary

RELATION OF BLOOD FLOW TO PRESSURE IN THE PULMONARY CIRCUIT

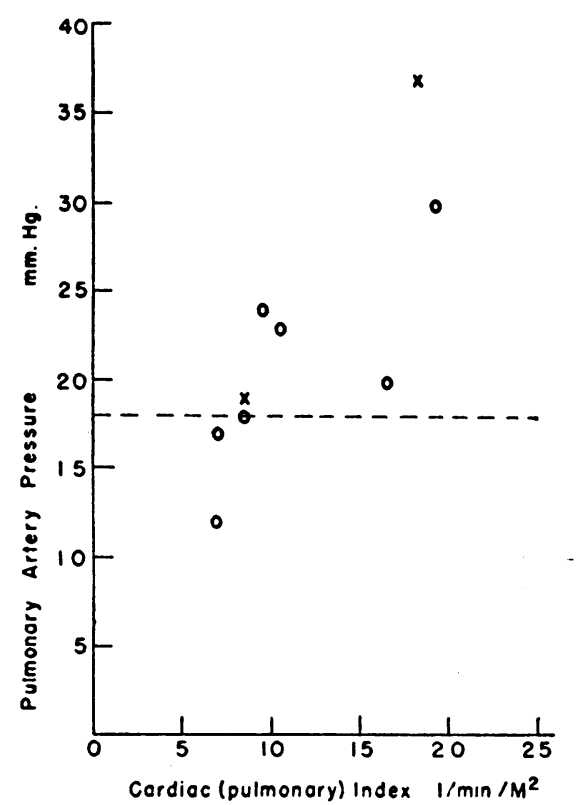

KEY

$0=$ Airial Septal Defect $x=$ Patent Ductus Arteriosus

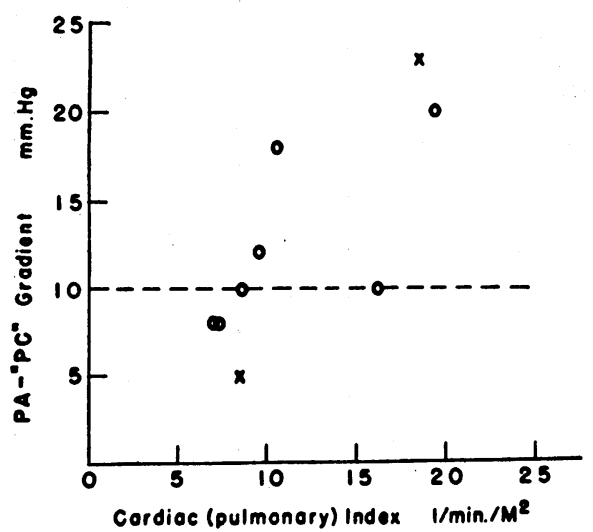

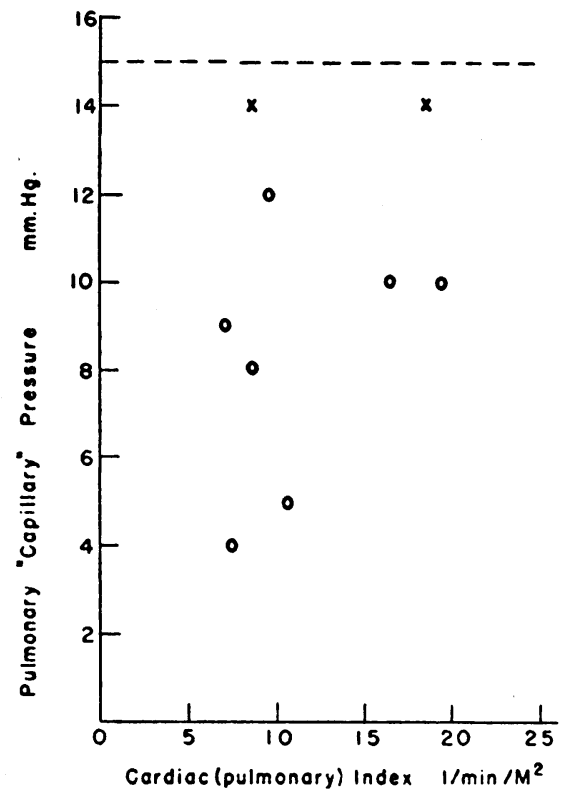

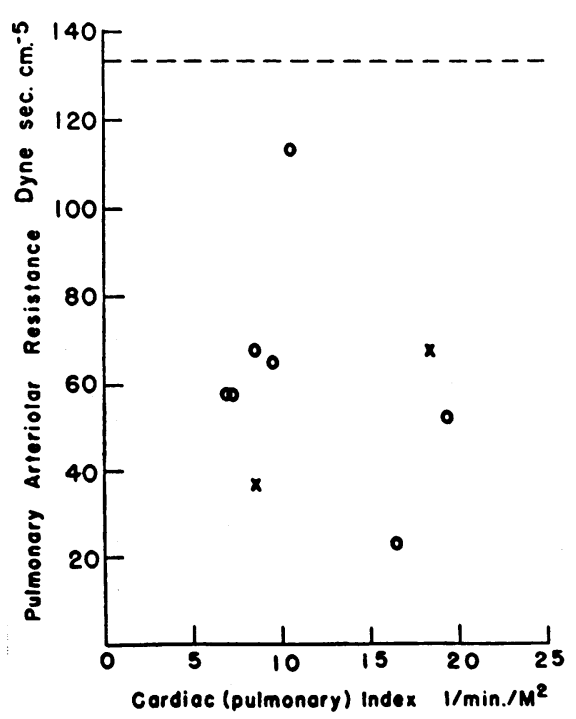

Fig. 1. Relation of Blood Flow to the Gradient of Pressure in Patients at Rest with UnCOMPLICATEd LEFT-TO-Right Shunts

Note the tendency to a wide pressure gradient as flows exceed about 10 liters per min. per sq.m. body surface. All pressures are mean values. 
arteriolar resistance were not included, all resistance values were normal in these particular patients.

\section{Comment}

A considerable elevation of pulmonary arterial pressure was seen in several of the patients listed in Table II. If the vasculature of the lung were composed of a system of rigid tubes, it would follow that any increase of blood flow would be associated with a corresponding rise of pressure. Such is not the case, however, until the blood flow reaches a value of approximately 10 liters per min. per sq.m. body surface. Above this point increased flow is accompanied by an increased pressure gradient from which one may conclude that the limit of passive or active dilatation of the pulmonary vessels has been reached and that the gradient of pressure must increase in order to produce greater blood flows. This increased pressure gradient apparently involves only the precapillary vessels. The pulmonary "capillary" pressure remains normal and it seems justifiable to assume that the post-capillary pressure gradient remains normal. Pulmonary arteriolar resistance was low in the majority of the cases in Table II. Cournand, Riley, and Himmelstein (24) have recently observed that in patients who had had unilateral pneumonectomies, the pulmonary artery pressure rose on exercise at flows of about 5 liters per min. per sq.m. body surface. Although this checks well with our figures in patients at rest with both lungs intact, it is to be emphasized that our patients are not comparable to normal indi- viduals with large pulmonary blood flows as a result of exercise, since we have observed (15) rises of pressure in the pulmonary arteries of normal individuals on exercising in the supine position with pulmonary blood flows of 5.5 to 6.0 liters per min. per sq.m. body surface. It seems likely, therefore, that the pulmonary vascular bed of individuals with large left-to-right shunts of long duration are more dilated at a given pressure than are those of normal individuals. In the latter situation, the increased pulmonary blood flow is of abrupt onset. In the patients here reported, the increased pulmonary blood flow was of many years' duration so that circulatory adjustments had probably taken place.

\section{EFFECTS OF ELEVATED PULMONARY ARTERIAL PRESSURES}

It will be recalled that the congenital cardiac defect known as Eisenmenger's complex consists of an aorta straddling both right and left ventricles (dextroposition of the aorta), a defect of variable size in the ventricular septum, and no pulmonic stenosis (25). Right ventricular hypertrophy is regularly present. Although there is at least some septum separating the two ventricles, physiologically both ventricles, in systole, act as a common chamber, as their systolic pressures are identical (26). Both the aorta and the pulmonary artery, therefore, receive blood at the same pressure head from a physiologically (not anatomically) common ventricle.

Three patients were recognized to have Eisenmenger's complex by venous catheterization, as

TABLE III

Pulmonary pressures, flows, and arteriolar resistances in Eisenmenger's complex

\begin{tabular}{|c|c|c|c|c|c|c|c|c|c|c|c|c|c|c|c|c|c|}
\hline \multirow[b]{3}{*}{ 苞 } & \multirow{3}{*}{ 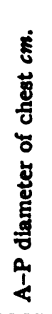 } & \multicolumn{9}{|c|}{ Pressures $\mathrm{mm} . \mathrm{Hg}$} & \multirow{2}{*}{\multicolumn{2}{|c|}{$\begin{array}{c}\text { Oxygen } \\
\text { consumption } \\
c c . / m i n .\end{array}$}} & \multirow{3}{*}{ 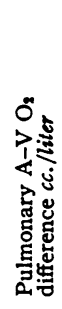 } & \multirow{3}{*}{ 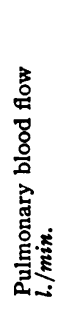 } & \multirow{3}{*}{ 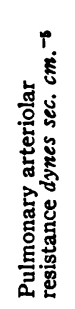 } & \multirow[b]{3}{*}{ 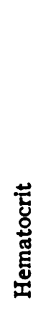 } & \multirow{3}{*}{ 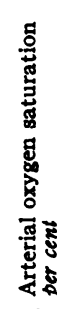 } \\
\hline & & \multicolumn{2}{|c|}{$\begin{array}{l}\text { Brachial } \\
\text { artery }\end{array}$} & \multicolumn{2}{|c|}{$\begin{array}{c}\text { Right } \\
\text { ventricle }\end{array}$} & \multicolumn{3}{|c|}{$\begin{array}{c}\text { Pulmonary } \\
\text { artery }\end{array}$} & \multirow{2}{*}{ 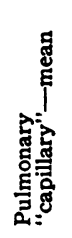 } & \multirow{2}{*}{ 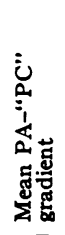 } & & & & & & & \\
\hline & & 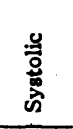 & 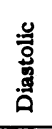 & 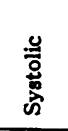 & 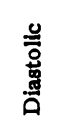 & 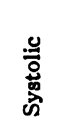 & 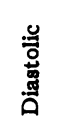 & $\sum_{\Sigma}^{5}$ & & & 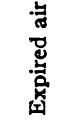 & 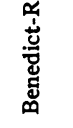 & & & & & \\
\hline $\begin{array}{l}\text { E. B. } \\
\text { E. G. } \\
\text { A. G. }\end{array}$ & $\begin{array}{l}20 \\
21 \\
16\end{array}$ & $\begin{array}{l}115 \\
118 \\
126\end{array}$ & $\begin{array}{l}71 \\
74 \\
81\end{array}$ & $\begin{array}{l}114 \\
117 \\
127\end{array}$ & $\begin{array}{r}-1 \\
1 \\
12\end{array}$ & $\begin{array}{l}115 \\
117 \\
127\end{array}$ & $\begin{array}{l}58 \\
56 \\
81\end{array}$ & $\begin{array}{r}78 \\
81 \\
102\end{array}$ & $\begin{array}{r}8 \\
2 \\
13\end{array}$ & $\begin{array}{l}70 \\
79 \\
89\end{array}$ & $\begin{array}{l}\overline{213} \\
180\end{array}$ & $\begin{array}{l}179 \\
215 \\
165\end{array}$ & $\begin{array}{l}44 \\
63 \\
77\end{array}$ & $\begin{array}{l}4.1 \\
3.4 \\
2.3\end{array}$ & $\begin{array}{l}1365 \\
1858 \\
3090\end{array}$ & $\begin{array}{l}51 \\
72 \\
72\end{array}$ & $\begin{array}{l}90 \\
85 \\
80\end{array}$ \\
\hline
\end{tabular}

PA = Pulmonary artery mean pressure.

"PC" = Pulmonary "capillary" mean pressure. 
described elsewhere (26). The salient characteristics were that the systolic pressures in the brachial artery, pulmonary artery, and right ventricle were identical when recorded simultaneously. Levoposition of the pulmonary artery (27) was excluded by the finding of venous blood in the pulmonary artery. The calculation of pulmonary blood flow was based on the assumpton that pulmonary venous blood was 98 per cent saturated with oxygen.

Table III presents the findings in the three patients with Eisenmenger's complex. The pulmonary arterial pressures were extremely high, while those in the pulmonary "capillaries" were entirely normal. Pulmonary artery blood flow was normal or decreased. The arteriolar resistances were enormous, being similar to or greater in magnitude than those in the normal systemic circuit.

\section{Comment}

It is not the purpose to discuss here the circulatory aspects and clinical course of Eisenmenger's complex, as this is treated in detail in another communication (26). From the point of view of pulmonary circulatory dynamics, it is of interest that there is a high resistance to blood flow through the pulmonary arterioles.

Normally, the arteriolar resistance in the lung is 67 dynes seconds $\mathrm{cm}^{-5}$ (Table $\mathrm{I}$ ), that in the peripheral circuit being about 1000 to 1200 (14). If these two resistances remained normal in the face of Eisenmenger's complex, survival would be shortlived because 1) most of the blood put out by the common ventricle would go to the low resistance area of the lungs, leaving little to go out the aorta, with death resulting; 2) if the high pressure of the common ventricle was maintained, which is unlikely under the above conditions, the pulmonary capillaries would be subjected to extremely elevated pressures which would result in pulmonary edema and death. As a matter of fact, neither occurs because of the high pulmonary arteriolar resistance. Pressures are maintained normal for the systemic circuit and high for the pulmonary circuit, blood-flows through the lung and through the periphery remain adequate for years, and the shunt from right-to-left and leftto-right remains minimal due to the essentially equal resistance offered by the pulmonary arte- rioles on the one hand and the systemic arterioles on the other, as Bing, Vandam, and Gray (16) first showed and we have confirmed (26). Bing and his associates did not measure pulmonary "capillary" pressure, but in calculating resistance assumed a pulmonary capillary or left auricular pressure of zero. Their estimated resistances were of the same order of magnitude as those reported here.

The mechanism of the increased pulmonary arteriolar resistance in Eisenmenger's complex is not entirely clear. In patients with the tetralogy of Fallot, with hematocrit values as high or higher, pulmonary arteriolar resistance may be of the order of 200 to 300 dynes seconds $\mathrm{cm}^{-5}$ (15), but not of the magnitude seen in Eisenmenger's complex. Increased viscosity of blood, therefore, plays only a small rôle in the increased resistance in these cases.

Motley and his colleagues (17) have observed that in response to breathing low oxygen gas mixtures, the pulmonary artery pressure rises. Pulmonary "capillary" pressures were not recorded but estimated pulmonary resistance doubled. This likewise would represent only a fraction of the resistance seen in Eisenmenger's complex with a similar degree of arterial oxygen unsaturation.

It seems plausible to assume that the arteriolar resistance is due primarily to a reduction in the size of the arteriolar lumens, but the mechanism by which the lumen becomes narrowed is not known. The peripheral capillaries are apparently protected from high arterial pressures through the intervention of arteriolar resistance, and it seems possible that the pulmonary capillaries might benefit by a similar protective mechanism. Although the pulmonary circulation acts in a seemingly passive manner over a wide range of physiologic conditions, there is a highly organized vasomotor activity which comes into play under certain conditions. Perhaps the best examples are those observed by Smith (28) and by ourselves (29) wherein marked pulmonary hypertension occurs due to arteriolar constriction as a result of experimental pulmonary embolism, and by Dirken and Heemstra (30) who showed intense pulmonary constriction in experimental anoxia of the lung exposed to nitrogen while the opposite lung was exposed to oxygen. 
D. THE EFFECT OF INCREASED PULMONARY "CAPILLARY" PRESSURE

Eleven patients were identified as having mitral stenosis by the typical murmur, with confirmatory history and laboratory signs. Eleven other patients were considered to have left ventricular failure as indicated by the presence of cardiac enlargement, exertional dyspnea, orthopnea, or evi- dence of pulmonary congestion. The influence of the elevated pulmonary "capillary" pressures found in these patients on other aspects of the pulmonary circulation has been studied.

Pertinent data are seen in Table IV and Figure 2. It will be seen that as the pulmonary "capillary" pressure rose above $15 \mathrm{~mm}$. $\mathrm{Hg}$, which is our upper limit of normal (2), the pulmonary

EFFECT OF AN ELEVATED PULMONARY CAPILLARY PRESSURE ON PULMONARY HEMODYNAMICS
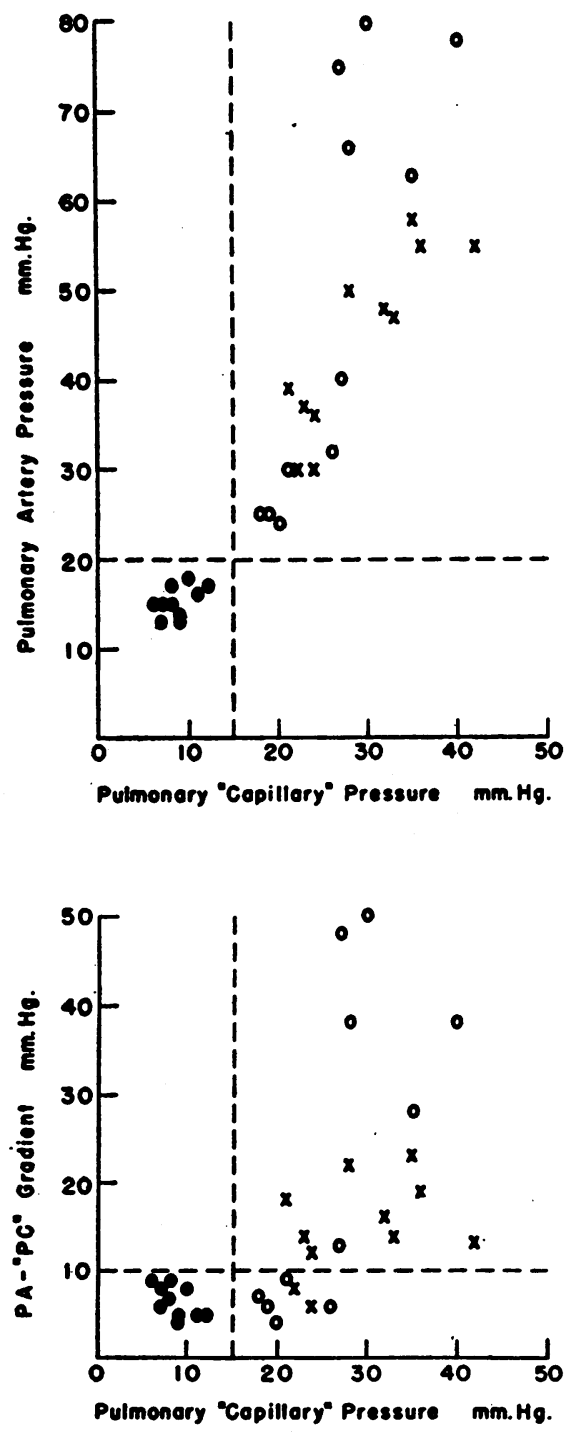

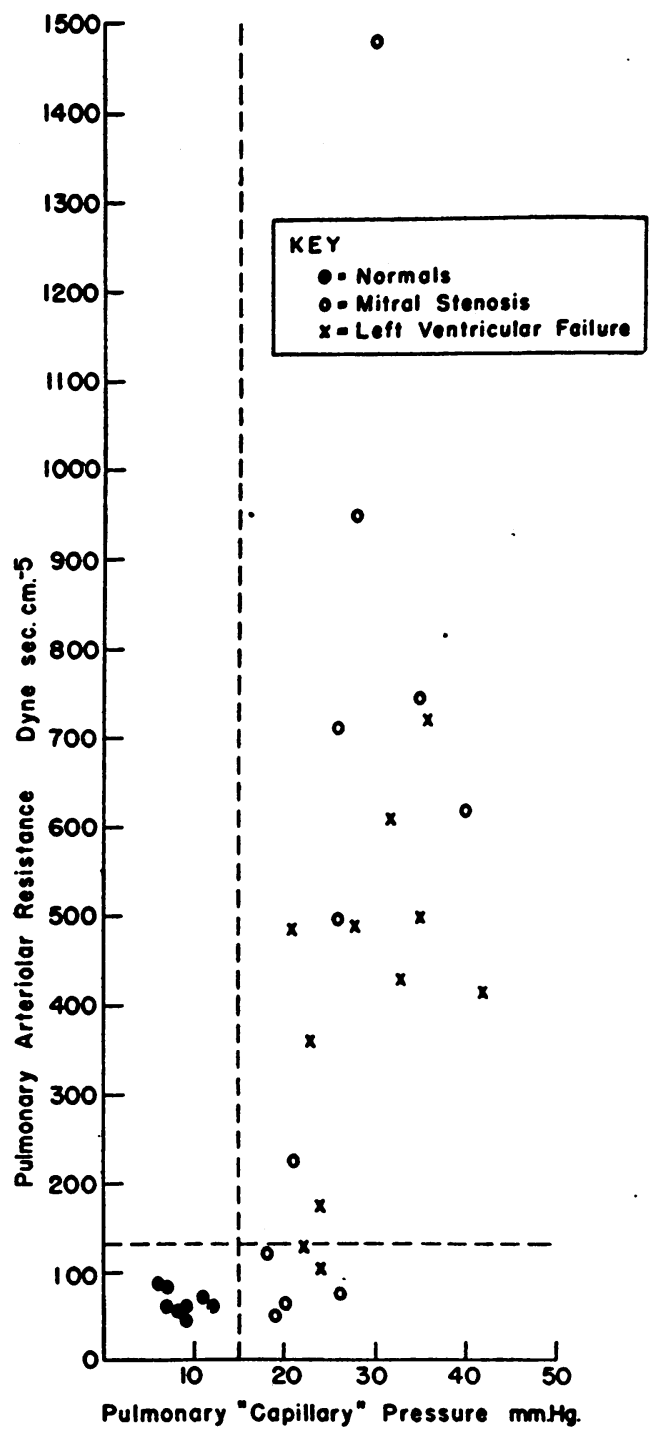

Fig. 2. Relation of Pulmonary “Capillary” Pressure to Pulmonary Arterial Pressure, Pressure Gradient, and Pulmonary Arteriolar Resistance

Note a rise in these factors as pulmonary "capillary" pressure exceeds about $25 \mathrm{~mm}$. Hg. All pressures are mean values. 
TABLE IV

Pulmonary pressures, flows, and arteriolar resistances in patients with mitral stenosis and left ventricular failure

\begin{tabular}{|c|c|c|c|c|c|c|c|c|c|c|c|}
\hline \multirow[b]{2}{*}{ 营 } & \multirow{2}{*}{ 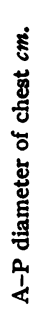 } & \multicolumn{2}{|c|}{ 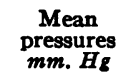 } & \multirow{2}{*}{ 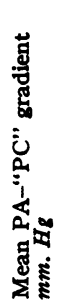 } & \multicolumn{2}{|c|}{$\begin{array}{c}\text { Oxygen } \\
\text { consumption } \\
\text { cc./min. }\end{array}$} & \multirow{2}{*}{ 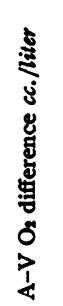 } & \multirow{2}{*}{ 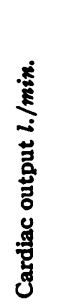 } & \multirow{2}{*}{ 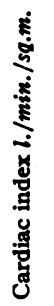 } & \multirow{2}{*}{ 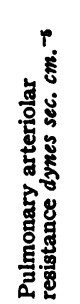 } & \multirow[b]{2}{*}{ Diagnosis } \\
\hline & & 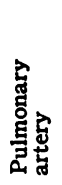 & 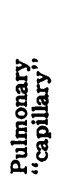 & & 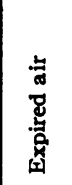 & 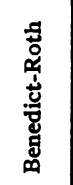 & & & & & \\
\hline $\begin{array}{l}\text { K. O. } \\
\text { M. G. } \\
\text { L. C. } \\
\text { M. W. } \\
\text { M. H. } \\
\text { D. V. } \\
\text { L. B. } \\
\text { M. T. } \\
\text { J. D. } \\
\text { J. F. } \\
\text { N. L. } \\
\text { G. B. }\end{array}$ & $\begin{array}{l}21 \\
19 \\
18 \\
20 \\
17 \\
13 \\
17 \\
20 \\
18 \\
22 \\
19 \\
16\end{array}$ & $\begin{array}{l}78 \\
80 \\
75 \\
40 \\
25 \\
63 \\
24 \\
30 \\
25 \\
32 \\
66 \\
39\end{array}$ & $\begin{array}{l}40 \\
30 \\
27 \\
27 \\
18 \\
35 \\
20 \\
21 \\
19 \\
26 \\
28 \\
21\end{array}$ & $\begin{array}{r}38 \\
50 \\
48 \\
13 \\
7 \\
28 \\
4 \\
9 \\
6 \\
6 \\
38 \\
18\end{array}$ & $\begin{array}{l}\overline{-} \\
260 \\
219 \\
163 \\
203 \\
196 \\
281 \\
254 \\
272 \\
193\end{array}$ & $\begin{array}{l}297 \\
176 \\
\overline{155} \\
\frac{1}{164} \\
182 \\
\frac{-}{179} \\
-\end{array}$ & $\begin{array}{l}61 \\
65 \\
48 \\
73 \\
48 \\
54 \\
42 \\
62 \\
30 \\
39 \\
86 \\
63\end{array}$ & $\begin{array}{l}4.9 \\
2.7 \\
5.4 \\
2.1 \\
4.6 \\
3.0 \\
4.8 \\
3.2 \\
9.4 \\
6.5 \\
3.2 \\
3.1\end{array}$ & $\begin{array}{l}2.4 \\
2.0 \\
3.3 \\
1.4 \\
3.0 \\
2.6 \\
3.3 \\
2.4 \\
5.2 \\
3.8 \\
1.9 \\
2.4\end{array}$ & $\begin{array}{r}619 \\
1480 \\
711 \\
495 \\
122 \\
746 \\
67 \\
225 \\
51 \\
74 \\
950 \\
464\end{array}$ & $\begin{array}{l}\text { Mitral stenosis } \\
\text { Mitral stenosis, tricuspid insufficiency } \\
\text { Mitral stenosis } \\
\text { Mitral stenosis and insufficiency } \\
\text { Mitral stenosis } \\
\text { Mitral stenosis } \\
\text { Mitral stenosis and insufficiency } \\
\text { Mitral and aortic stenosis and insufficiency } \\
\text { Mitral stenosis } \\
\text { Mitral stenosis } \\
\text { Mitral stenosis } \\
\text { Active rheumatic heart disease with mitral }\end{array}$ \\
\hline $\begin{array}{l}\text { C. C. } \\
\text { N. L. } \\
\text { A. L. } \\
\text { S. M. } \\
\text { N. V. } \\
\text { E. L. } \\
\text { C. K. } \\
\text { W. L. } \\
\text { G. M. } \\
\text { M. G. }\end{array}$ & $\begin{array}{l}23 \\
15 \\
22 \\
23 \\
27 \\
20 \\
22 \\
20 \\
22 \\
20\end{array}$ & $\begin{array}{l}55 \\
47 \\
50 \\
37 \\
58 \\
36 \\
30 \\
55 \\
30 \\
48\end{array}$ & $\begin{array}{l}36 \\
33 \\
28 \\
23 \\
35 \\
24 \\
22 \\
42 \\
24 \\
32\end{array}$ & $\begin{array}{r}19 \\
14 \\
22 \\
14 \\
23 \\
12 \\
8 \\
13 \\
6 \\
16\end{array}$ & $\begin{array}{l}\frac{226}{-} \\
\overline{263} \\
\overline{-} \\
250 \\
189 \\
243 \\
192\end{array}$ & $\begin{array}{c}-\overline{152} \\
318 \\
232 \\
302 \\
257 \\
285 \\
190 \\
215 \\
-\end{array}$ & $\begin{array}{r}108 \\
58 \\
88 \\
84 \\
81 \\
47 \\
50 \\
75 \\
54 \\
91\end{array}$ & $\begin{array}{l}2.1 \\
2.6 \\
3.6 \\
3.1 \\
3.7 \\
5.5 \\
5.0 \\
2.5 \\
4.5 \\
2.1\end{array}$ & $\begin{array}{l}1.2 \\
2.2 \\
1.6 \\
1.7 \\
1.7 \\
3.5 \\
3.1 \\
1.5 \\
2.4 \\
1.3\end{array}$ & $\begin{array}{l}723 \\
430 \\
488 \\
361 \\
497 \\
174 \\
128 \\
416 \\
107 \\
609\end{array}$ & $\begin{array}{l}\text { Arteriosclerotic heart disease with failure } \\
\text { Active rheumatic carditis with failure } \\
\text { Cardiac failure, ? cause } \\
\text { Arteriosclerotic heart disease with failure } \\
\text { Cardiac failure, ? cause } \\
\text { Cardiac failure, ? cause } \\
\text { Hypertensive heart disease with failure } \\
\text { Cardiac failure, ? cause } \\
\text { Arteriosclerotic heart disease with failure } \\
\text { Arteriosclerotic heart disease with failure }\end{array}$ \\
\hline
\end{tabular}

artery pressure rose proportionally until a value of about 20 to $25 \mathrm{~mm}$. $\mathrm{Hg}$ for pulmonary "capillary" pressure was reached. At this point the pulmonary artery pressure began to rise precipitously, the PA-"PC" gradient to widen, and the arteriolar resistance to increase. In one instance of mitral stenosis, the resistance and pressure in the pulmonary artery approximated that of the systemic circuit.

\section{Comment}

From these data, certain conclusions seem justified. The "capillary" pressure in the lungs becomes elevated in mitral stenosis and left ventricular failure. Evidence indicates that the values obtained by the technique used represent minimal ones and are probably 2 or $3 \mathrm{~mm}$. $\mathrm{Hg}$ lower than the true capillary pressure in the lungs (31).

The height which the "capillary" pressure reached was somewhat of a surprise to us. Taking into account all errors in recording, the effect of an arbitrary zero point in relation to the actual tip of the catheter, and the effect of respiratory influences on the pressures in these vessels, it is still apparent that the pulmonary "capillary" pressure, as recorded at rest in some of the patients, was above the colloid osmotic pressure of the blood. It might be argued that the thickening of the capillary basement membrane in mitral stenosis (32) held back water and hence prevented pulmonary edema. This might be a factor in slowing edema formation in acute stress situations, but it is difficult to conceive of its preventing edema in the face of a prolonged elevation of pressure in the lung capillaries unless it is postulated that the endothelium is impermeable, which of course is not the case, since pulmonary edema does occur. Little is known of the tissue pressure in the lung, either in normal conditions or in patients with chronic passive congestion of the lung. It seems probable that tissue pressure around capillaries is equivalent to intra-alveolar pressure under normal conditions; whether engorgement of capillaries and thickening of alveolar walls would 
permit a rise in tissue pressure is conjectural. It is our belief that the absence of gross pulmonary edema in these patients with "capillary" pressures well in excess of $25 \mathrm{~mm}$. $\mathrm{Hg}$ at rest cannot easily be explained by an increased tissue pressure in the lungs but by the hypothesis that part of the observed elevation of "capillary" pressure was transient and incidental to the stress of the catheterization procedure.

As pulmonary "capillary" pressure increased, pressure in the pulmonary artery at first rose pari passu, the PA-"PC" gradient remaining unchanged. With "capillary" pressures in excess of 20 to $25 \mathrm{~mm}$. Hg, however, this being about the osmotic pressure of plasma (14), the pressure in the pulmonary artery and the PA-"PC" gradient increased out of all proportion to the rise of "capillary" pressure. In some instances, the pulmonary hypertension was extreme.

The mechanism of these disproportionately high pressures in the pulmonary artery was found in the increased arteriolar resistance. In four patients with mitral stenosis and in two with left ventricular failure, pulmonary arteriolar resistance was normal. The highest pulmonary "capillary" pressure among these was $26 \mathrm{~mm}$. $\mathrm{Hg}$, the others being less than $25 \mathrm{~mm}$. $\mathrm{Hg}$. The remainder of the patients had increased resistances which did not, however, show a linear relationship to the "capillary" pressure. Some individuals showed increases in resistance with pulmonary "capillary" pressures in the twenties and others to a much less extent with pressures in the thirties. In any event, resistances were extremely elevated in a few patients, particularly in those with mitral stenosis. In two, the resistances were 950 and 1480 dynes seconds $\mathrm{cm}^{-5}$ respectively, which were roughly 14 and 22 times the normal. Dyspnea in these two patients was incapacitating. The elevated pulmonary artery pressures reported in left ventricular failure and mitral stenosis by others $(12,33)$ is readily attributable to the mechanism described.

The nature of the increased resistance is speculative but appears most likely to be on the basis of arteriolar constriction. In any event, it might be looked upon as a compensatory mechanism preventing to some extent sudden increases in flow through the capillaries to the incompetent left ventricle or to the narrow mitral valve and there- fore protecting the pulmonary capillaries from a high hydrostatic pressure and pulmonary edema.

\section{SUMMARY}

1. Pulmonary hemodynamics have been studied in normal individuals at rest and the response of the pulmonary vasculature to large pulmonary blood flows, high pulmonary arterial pressures, and elevated pulmonary "capillary" pressures has been analyzed.

2. In eight normal patients at rest but not in a basal state, the average mean pulmonary artery pressure was $15 \mathrm{~mm}$. $\mathrm{Hg}$, the average mean pulmonary "capillary" pressure was $9 \mathrm{~mm}$. $\mathrm{Hg}$, the average gradient of pressure between the two was $6 \mathrm{~mm}$. $\mathrm{Hg}$, and the average arteriolar resistance was 67 dynes seconds $\mathrm{cm}^{-5}$ The average work of the right ventricle against pressure or more properly the pulmonary peripheral work was $0.89 \mathrm{~kg}$. m. per min. per sq.m. body surface.

3. The relation of large pulmonary blood flows to the pressure gradient from pulmonary artery to pulmonary "capillaries" was studied at rest in patients with uncomplicated patent ductus arteriosus and atrial septal defect. The gradient of pressure across the lung widened when the pulmonary blood flow exceeded approximately 10 liters per min. per sq.m. of body surface.

4. In three patients with Eisenmenger's complex with pulmonary arterial pressures which were essentially aortic in magnitude, the resistance to blood flow offered by the pulmonary arterioles was of the same order of magnitude as that in the systemic circuit.

5. Elevated pulmonary "capillary" pressures were consistently found in patients with mitral stenosis and left ventricular failure. When the pulmonary "capillary" pressure rose to values of about $25 \mathrm{~mm}$. $\mathrm{Hg}$, the pressure in the pulmonary artery rose proportionately, the pulmonary arterypulmonary "capillary" pressure gradient and the pulmonary arteriolar resistance remained normal. With pulmonary "capillary" pressures in excess of $25 \mathrm{~mm}$. $\mathrm{Hg}$ (the approximate osmotic pressure of plasma), pressure in the pulmonary artery rose disproportionately, the PA-"PC" pressure gradient widened, and the pulmonary arteriolar resistance increased on occasion to 20 or more times the normal value. 


\section{ACKNOWLEDGMENTS}

We wish to express our appreciation to Miss Barbara Jacobs and Mrs. Harriet Kriete for their technical assistance.

\section{BIBLIOGRAPHY}

1. Cournand, A., and Ranges, H. A., Catheterization of right auricle. Proc. Soc. Exper. Biol. \& Med., 1941, 46, 462.

2. Hellems, H. K., Haynes, F. W., and Dexter, L., Pulmonary "capillary" pressure in man. J. Applied Physiol., 1949, 2, 24.

3. Peters, J. P., and Van Slyke, D. D., Quantitative Clinical Chemistry, Vol. II, Methods. Williams \& Wilkins, Baltimore, 1932.

4. Dexter, L., Haynes, F. W., Burwell, C. S., Eppinger, E. C., Seibel, R. E., and Evans, J. M., Studies of congenital heart disease. I. Technique of venous catheterization as a diagnostic procedure. J. Clin. Invest., 1947, 26, 547.

5. Hamilton, W. F., Brewer, G., and Brotman, I., Pressure pulse contours in the intact animal. $I$. Analytical description of a high-frequency hypodermic manometer with illustrative curves of simultaneous arterial and intracardiac pressures. Am. J. Physiol., 1934, 107, 427.

6. Rappaport, M., and Sarnoff, S. J., An electronic multi-range multi-channel direct-writing pressure recorder. Federation Proc., 1949, 8, 130.

7. Miller, W. S., The Lung. Charles C. Thomas, Springfield, 1937.

8. Remington, J. W., and Hamilton, W. F., The evaluation of the work of the heart. Am. J. Physiol., 1947, 150, 292.

9. Prec, O., Katz, L. N., Rosenman, R., and Sennett, L. W., Estimate of the kinetic and potential energy of the work of the human heart. Federation Proc., 1949, 8, 128.

10. Riley, R. L., Himmelstein, A., Motley, H. L., Weiner, H. M., and Cournand, A., Studies of the pulmonary circulation at rest and during exercise in normal individuals and in patients with chronic pulmonary disease. Am. J. Physiol., 1948, 152, 372.

11. Houssay, B. A., Lewis, J. T., Orías, O., Menéndez, E. B., Foglia, V., and Hug, E., Fisiología Humana. El Aténco, Buenos Aires, 1945, p. 201.

12. Hickam, J. B., and Cargill, W. H., Effect of exercise on cardiac output and pulmonary arterial pressure in normal persons and in patients with cardiovascular disease and pulmonary emphysema. $\mathrm{J}$. Clin. Invest., 1948, 27, 10.

13. Lyons, R. H., Kennedy, J. A., and Burwell, C. S., The measurement of venous pressure by direct method. Am. Heart J., 1938, 16, 675.

14. Landis, E. M., Capillary pressure and capillary permeability. Physiol. Rev., 1934, 14, 404.

15. Unpublished observations.
16. Bing, R. J., Vandam, L. D., and Gray, F. D., Jr., Physiological studies in congenital heart disease. III. Results obtained in five cases of Eisenmenger's complex. Bull. Johns Hopkins Hosp., 1947, 80, 323.

17. Motley, H. L., Cournand, A., Werko, L., Himmelstein, A., and Dresdale, D., The influence of short periods of induced acute anoxia upon pulmonary artery pressures in man. Am. J. Physiol., 1947, 150,315 .

18. Hickam, J. B., The pulmonary vascular resistance. J. Clin. Invest., 1949, 28, 788.

19. Hickam, J. B., Atrial septal defect. A study of intracardiac shunts, ventricular outputs, and pulmonary pressure gradients. Am. Heart J., 1949, 38, 801.

20. Cournand, A., Riley, R. L., Breed, E. S., Baldwin, E. deF., and Richards, D. W., Jr., Measurement of cardiac output in man using the technique of catheterization of the right auricle or ventricle. J. Clin. Invest., 1945, 24, 106.

21. Hickam, J. B., Cargill, W. H., and Golden, A., Cardiovascular reactions to emotional stimuli. Effect on the cardiac output, arteriovenous oxygen difference, arterial pressure, and peripheral resistance. J. Clin. Invest., 1948, 27, 290.

22. Bolomey, A. A., Michie, A. J., Michie, C., Breed, E. S., Schreiner, G. E., and Lauson, H. D., Simultaneous measurement of effective renal blood flow and cardiac output in resting normal subjects and patients with essential hypertension. J. Clin. Invest., 1949, 28, 10.

23. Dexter, L., Haynes, F. W., Burwell, C. S., Eppinger, E. C., Sosman, M. C., and Evans, J. M., Studies of congenital heart disease. III. Venous catheterization as a diagnostic aid in patent ductus arteriosus, tetralogy of Fallot, ventricular septal defect, and auricular septal defect. J. Clin. Invest., 1947, 26, 561.

24. Cournand, A., Riley, R. L., and Himmelstein, A., Pulmonary blood flow and alveolar ventilationperfusion relationship following resection of one lung in man. Federation Proc., 1949, 8, 30.

25. Eisenmenger, V., Die angeborenen Defekte der Kammerscheidewand des Herzens. Ztschr. f. klin. Med., 1897, 32, (supplement), 1.

26. Dow, J. W., Goodale, W. T., Ferris, B. G., Haynes, F. W., Whittenberger, J. L., Eppinger, E. C., and Dexter, L., Studies of congenital heart disease. V. Eisenmenger's complex. To be published.

27. Taussig, H. B., and Bing, R. J., Complete transposition of the aorta and levoposition of the pulmonary artery. Clinical, physiological, and pathological findings. Am. Heart J., 1949, 37, 551.

28. Smith, J. R., and Hara, M., Cardiovascular dynamics in experimental embolism of restricted portions of the lungs. J. Clin. Invest., 1948, 27, 556.

29. Haynes, F. W., Kinney, T. D., Hellems, H. K, and Dexter, $\mathrm{L}$, Circulatory changes in experimental 
pulmonary embolism. Federation Proc., 1947, 6, 125.

30. Dirken, M. N. J., and Heemstra, H., Alveolar oxygen tension and lung circulation. Quart. J. Exper. Physiol., 1948, 34, 193.

31. Hellems, H. K., Haynes, F. W., Dexter, L., and Kinney, T. D., Pulmonary capillary pressure in animals estimated by venous and arterial catheterization. Am. J. Physiol., 1948, 155. 98.
32. Parker, F., Jr., and Weiss, S., Nature and significance of structural changes in lungs in mitral stenosis. Am. J. Path., 1936, 12, 573.

33. Bloomfield, R. A., Lauson, H. D., Cournand, A., Breed, E. S., and Richards, D. W., Jr., Recording of right heart pressure in normal subjects and in patients with chronic pulmonary disease and various types of cardio-circulatory diseases. J. Clin. Invest., 1946, 25, 639. 